International Journal of Current Advanced Research

ISSN: O: 2319-6475, ISSN: P: 2319 - 6505, Impact Factor: SJIF: 5.995

Available Online at www.journalijcar.org

Volume 6; Issue 5; May 2017; Page No. 3791-3795

DOI: http://dx.doi.org/10.24327/ijcar.2017.3795.0369

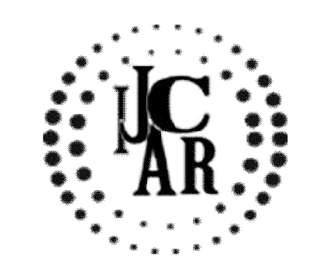

Research Article

\title{
APPLICATION OF BACK PROPAGATION NEURAL NETWORK IN PREDICTING NOX EMISSION FROM I. C. ENGINES
}

\section{Aunshuman Chatterjee ${ }^{1}$ and Ranjit Kumar Dutta ${ }^{2}$}

\author{
${ }^{1}$ Department of Mechanical Engg., GIMT, Azara, Guwahati, Assam, India \\ 2Department of Mechanical Engg., AEC, Jalukbari, Guwahati, Assam, India
}

\section{A R T I C L E I N F O}

\section{Article History:}

Received $16^{\text {th }}$ February, 2017

Received in revised form $12^{\text {th }}$ March, 2017

Accepted $27^{\text {th }}$ April, 2017

Published online $28^{\text {th }}$ May, 2017

\section{Key words:}

Emission, Neural Network (NN), Back propagation neural network (BPNN), RMS error

\begin{abstract}
A B S T R A C T
Our eco-system is being adversely affected by emissions from internal combustion (I.C.) engines. One of the prominent emissions of I.C engines are the nitrogenous products commonly known as $\mathrm{NO}_{\mathrm{X}}$. In the present work, an attempt has been made towards the application of Back Propagation Neural Network (BPNN) for predicting the $\mathrm{NO}_{\mathrm{X}}$ emission from a diesel engine so that better control of the engine parameters may be performed to minimize the level of emission. The data collected for training the Neural Network (NN) were compression ratio, injection timing, load, cylinder pressure, crank angle at peak pressure, temperature of cooling water, and temperature of exhaust gas and these inputs were strategically combined to predict $\mathrm{NO}_{\mathrm{X}}$ emission. It has been observed that by the right combination of input parameters to the $\mathrm{NN}$ may effectively predict the level of $\mathrm{NO}_{\mathrm{X}}$ emission with minimum Root Mean Squared (RMS) error of almost less than $7.5 \%$ for better control.
\end{abstract}

Copyright $₫ 2017$ Aunshuman Chatterjee and Ranjit Kumar Dutta. This is an open access article distributed under the Creative Commons Attribution License, which permits unrestricted use, distribution, and reproduction in any medium, provided the original work is properly cited.

\section{INTRODUCTION}

One of the banes of the modern society is the Automotive pollution because the exhaust emissions from them degrade the environment. The emissions an internal combustion (I.C.) engine delivers have adverse affect on human health as well as the plant kingdom. The increase in the number of vehicles has caused a voluminous increase in the pollutants such as hydrocarbons $(\mathrm{HC})$, nitrogen-oxides $\left(\mathrm{NO}_{\mathrm{x}}\right)$, Carbon monoxide (CO) and particulate matter (PM) at an alarming rate. Consistent research has caused a drastic change of technology which has converted the conventional I.C. engines into electronically controlled vehicles. Recent development in computer technology and sensor systems has made it possible to achieve better control over the pollutants. Yet in ideal sense, the concept of green vehicle is a dream of the future because the thrust of the research is towards the development of intelligent vehicle with decision making capability. The application of artificial neural network in I.C. engine systems is one such direction, as it has various capabilities such as self learning, parallel \& distributed processing and very large scale integration (VLSI) system implementation. Due to such attributes, Artificial Neural Network (ANN) has gained the attention of the researchers in the recent times for application

*Corresponding author: Aunshuman Chatterjee Mech. Engg., GIMT, Azara, Guwahati, Assam, India in IC engine technology. The use of ANN makes it possible to predict these emissions quite close to their actual values and hence better control may be achieved through a feedback loop in the hardware. Artificial Neural Network (ANN) is a general term which represents the model of human brain and its processing, developed by soft computing practitioners. Among its various types, one of the most popular techniques followed is back-propagation neural network (BPNN). This neural network is fed with example sets of data as inputs obtained from practical results, for example, from the data obtained during experiments in a diesel engine test rig by using various settings of the engine and observing the NO and $\mathrm{NO}_{2}$ (commonly known as $\mathrm{NO}_{\mathrm{x}}$ ) emission results at the exhaust. It is required to iterate the algorithm of BPNN repeatedly with the same sets of data so that the network produces calculated results of emission by using its algorithm, which is called predicted results of emission. These predicted results will be different, naturally to some extent, from the actual result of emission during the experiment and thus the calculation of RMS error may be done. This error is used during the iterations for improving the results of prediction and the name of back propagation comes from this fact.

The research aims at the study of the architecture and algorithm for the Back Propagation Neural Network (BPNN) and its features, to plan and strategise the data collected from a stationary diesel engine with sensors for subsequent use in BPNN and to examine the applicability of BPNN architecture of $\mathrm{ANN}$ in predicting the $\mathrm{NO}_{\mathrm{X}}$ emissions of I.C. engines. 


\section{Previous Research}

A survey is undertaken through the papers published by the research workers on the applicability of ANN to successfully predict the emissions from I.C. engine: Karakitsios et.al (2005) attempt was based on vehicle speed and vehicle's category traffic flow as inputs, to develop $\mathrm{NN}$ model and it with back propagation algorithm to calculate the emissions of $\mathrm{CO}, \mathrm{C}_{6} \mathrm{H}_{6}, \mathrm{NO}_{\mathrm{x}}$ and $\mathrm{PM}_{10}$ and the corresponding error (calculated $\mathrm{v} / \mathrm{s}$ observed values) was lower than $3 \%$ in a complex busy avenue environment [1].

Obodeh et.al (2009) experimented with a light duty Nissan diesel engine test rig to measure engine operating parameters and its tail pipe emissions. Levenberg-Marquardt (LM) algorithm was used to train the ANN on experimental data using in different architectures of back propagation to predict the oxides of nitrogen $\left(\mathrm{NO}_{\mathrm{x}}\right)$ emissions under various operating variables. For pre-specified engine speeds and loads with LM algorithm, absolute percentage errors were found between $0.68 \%$ to $3.34 \%$ [2].

M.Ali Akcayol et. al (2005) attempted to improve cold start performance of catalytic converters for $\mathrm{HC}$ and $\mathrm{CO}$ emissions with the help of a burner heated catalyst tested in a four stroke spark ignition engine using back propagation learning algorithms of ANN for prediction of catalyst temperature, $\mathrm{CO}$ and $\mathrm{HC}$ emissions. Taking the training dataset from the experiment, it was found that the deviation coefficients for standard and heated catalyst temperature are less than $4.925 \%$, and $1.602 \%$, the same for standard and heated catalyst $\mathrm{HC}$ emissions are less than $4.798 \%$ and $4.926 \%$ and that for standard and heated catalyst $\mathrm{CO}$ emissions are less than $4.82 \%$ and $4.938 \%$ respectively[3].

Shivakumar et.al (2010) used blends of Hunge oil with diesel at various compression ratios as fuel to predict the performance and emission characteristics of a single cylinder, four stroke, and water cooled compression ignition engine using Artificial neural networks (ANN's). The ANN was trained with back propagation algorithm using compression ratio, blend percentage and percentage load as input variables whereas performance parameters together with engine exhaust emissions were used as output variables. ANN showed good convergence between predicted and experimental values for various performance parameters and emissions with mean squared error closed to 1 and mean relative error less $9 \%[4]$.

\section{Research Method}

The entire experiment was carried out at the I.C Engine laboratory in a computerized single cylinder, four stroke, multi-fuel, variable compression ratio (VCR) engine as shown in Fig.1. The fuel used for the experiment was diesel. The setup consists of single cylinder, four stroke, multi-fuel, research engine (specified in Table 1) connected to eddy current type dynamometer for loading. The operation mode of the engine can be changed from Diesel to Petrol or from Petrol to Diesel with some necessary changes. In both the modes, the compression ratio can be varied without stopping the engine and without altering the combustion chamber geometry by specially designed tilting cylinder block arrangement. The injection point and spark point can be changed for research tests. Setup is provided with necessary instruments for measuring combustion pressure, diesel line pressure and crank-angle. These signals are interfaced with computer for pressure crank-angle diagrams. Instruments as shown in Table 2 are provided to interface airflow, fuel flow, temperatures and load measurements.

Table 1 Engine specifications

\begin{tabular}{|c|c|c|}
\hline Stroke & \multicolumn{2}{|c|}{$110 \mathrm{~mm}$} \\
\hline Bore & \multicolumn{2}{|c|}{$87.5 \mathrm{~mm}$} \\
\hline Capacity & \multicolumn{2}{|c|}{$661 \mathrm{cc}}$. \\
\hline \multirow{4}{*}{$\begin{array}{c}\text { Diesel } \\
\text { mode }\end{array}$} & Power & $3.5 \mathrm{KW}$ \\
\cline { 2 - 3 } & Speed & $1500 \mathrm{rpm}$ \\
\cline { 2 - 3 } & CR range & $0-25 \mathrm{Deg}$ BTDC \\
\cline { 2 - 3 } & Injection variation & $4.5 \mathrm{KW} @ 1800 \mathrm{rpm}$ \\
\cline { 2 - 3 } $\begin{array}{c}\text { Petrol } \\
\text { mode }\end{array}$ & Power & $1200-1800 \mathrm{rpm}$ \\
\cline { 2 - 3 } & Speed range & $0-1-10: 1$ \\
\hline \multirow{3}{*}{ Fuel tank } & CR range & 15 lit \\
\cline { 2 - 3 } & Cark variation & $\begin{array}{c}\text { Duel compartment, with } \\
\text { fuel metering pipe of glass }\end{array}$ \\
\cline { 2 - 3 } & Type &
\end{tabular}

Table 2 Instrumentation for measurement

\begin{tabular}{|c|c|c|}
\hline Dynamometer Type & \multicolumn{2}{|c|}{$\begin{array}{l}\text { Eddy current, water cooled, with } \\
\text { loading unit }\end{array}$} \\
\hline Propeller shaft & \multicolumn{2}{|c|}{ With universal joints } \\
\hline Air box & \multicolumn{2}{|c|}{$\begin{array}{l}\text { MS fabricated with orifice meter and } \\
\text { manometer }\end{array}$} \\
\hline Calorimeter Type & \multicolumn{2}{|c|}{ Pipe in pipe } \\
\hline \multirow[b]{2}{*}{ Crank angle sensor } & Resolution & 1 Deg \\
\hline & Speed & $\begin{array}{l}5500 \text { RPM with } \\
\text { TDC pulse }\end{array}$ \\
\hline Data acquisition device & NI USB & 6210,16 -bit, $250 \mathrm{kS} / \mathrm{s}$ \\
\hline \multirow[b]{2}{*}{ Piezo powering unit } & Make & Cuadra \\
\hline & Model & AX-409 \\
\hline \multirow{2}{*}{ Digital voltmeter } & Range & $0-20 \mathrm{~V}$ \\
\hline & Panel & Mounted \\
\hline \multirow{2}{*}{ Temperature sensor } & Type & RTD, PT100 \\
\hline & Thermocouple & Type K \\
\hline \multirow{3}{*}{ Thermometer } & Type & Two wire \\
\hline & Input & RTD PT100 \\
\hline & Range & $0-100$ Deg C \\
\hline \multirow{4}{*}{ Transmitter } & Output & 4-20 mA \\
\hline & Type & Two wire \\
\hline & $\begin{array}{c}\text { Input } \\
\text { Thermocouple } \\
\text { Range }\end{array}$ & 0-1200 Deg C \\
\hline & Output & $4-20 \mathrm{~mA}$ \\
\hline \multirow{2}{*}{ Load indicator } & Range & $0-50 \mathrm{Kg}$ \\
\hline & Supply & 230VAC \\
\hline \multirow{2}{*}{ Load sensor } & Type & Strain gauge \\
\hline & Range & $0-50 \mathrm{Kg}$ \\
\hline Fuel flow transmitter & Range & $0-500 \mathrm{~mm} \mathrm{WC}$ \\
\hline
\end{tabular}

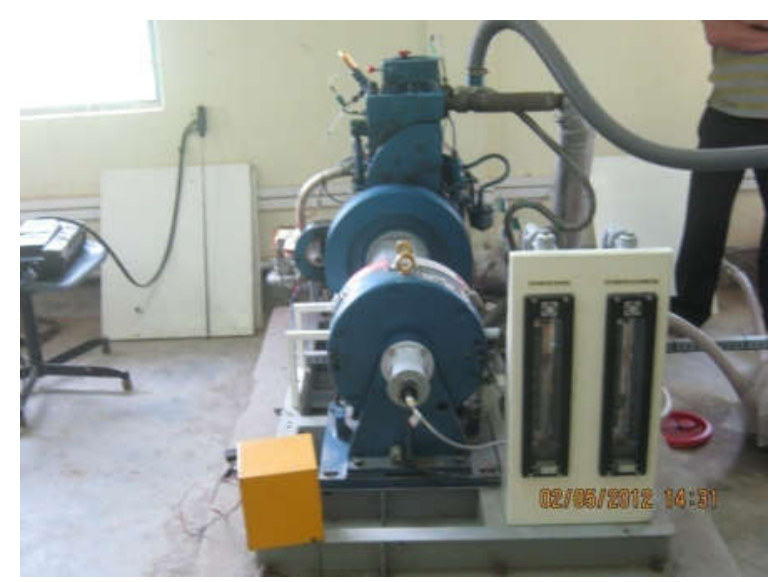

Fig.1 The engine test rig 


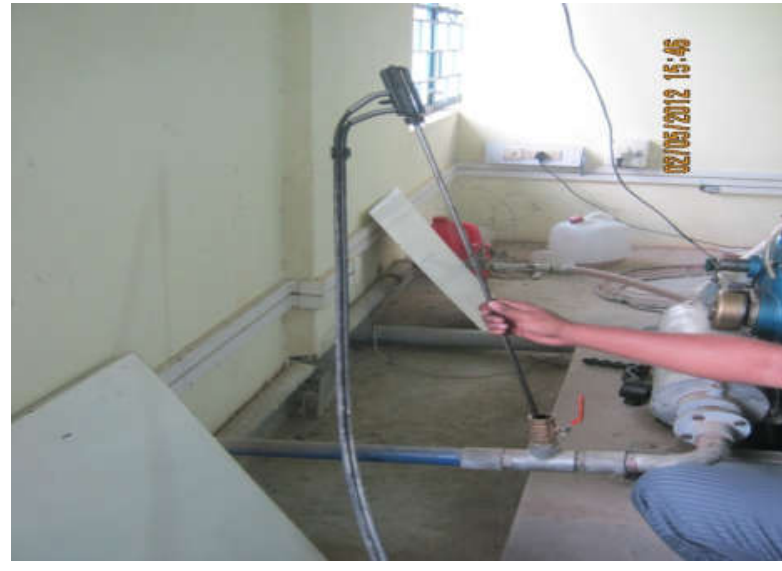

Fig. 2 Flue gas sensor stick inserted into the exhaust valve outlet

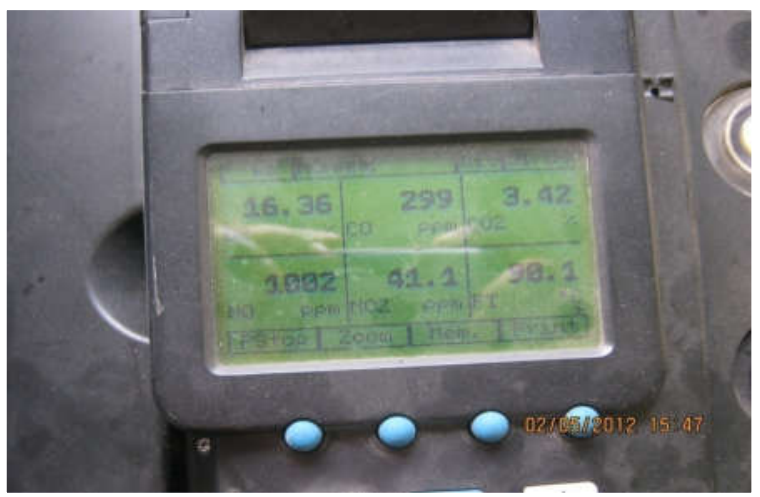

Fig. 3 Flue gas analyser showing $\mathrm{NO}_{\mathrm{X}}$ emission readings

Data on exhaust emission were collected by varying the controllable parameters of the engine among which are Compression Ratio (CR), Injection Timing (IT) and Load (W) on the engine are crucial. Fig. 3 and Fig.4 shows the technique adopted to measure $\mathrm{NO}_{\mathrm{x}}$ emission and the corresponding reading shown in the flue gas analyser respectively. Also the parameters such as observed load $\left(\mathrm{W}_{\mathrm{OBS}}\right)$, water inlet and outlet temperature to and from the engine respectively $\left(\mathrm{T}_{1} \&\right.$ $\mathrm{T}_{2}$ ) engine exhaust temperature $\left(\mathrm{T}_{5}\right)$ from calorimeter peak cylinder pressure(P.P), Crank angle corresponding to peak pressure $\left(\theta_{\text {peak }}\right)$, indicated air pressure in $\mathrm{mm}$ of water column in the calorimeter(Air pr.) and rate of fuel into the cylinder(R.F.I) were recorded.

In order to establish the domain of the experiment, we may consider each parameter or factor at several levels. For example, if we have three factors and if each factor has three levels, then the total number of experiments or observations or treatment conditions (TC) would be $3 \times 3 \times 3=27$. Similarly, we may use formula for calculating the total number of experiments as given below, if all the factors have the same number of levels:

$\mathrm{TC}=\mathrm{l}^{\mathrm{f}}$

where, $1=$ Number of levels

$\mathrm{f}=$ number of factors

Following the above concept, data for sixty three experiments by making CR (3 levels), IT (3 levels) and

$\mathrm{W}$ (7 levels), i.e. $\mathrm{TC}=3 \times 3 \times 7=63$

\section{Artificial Neural Networks Modelling}

The behaviour of a neuron can be captured by a simple model shown in Fig. 4 below which bears direct analogy to the actual constituents of a biological neuron and hence it is called artificial neuron.

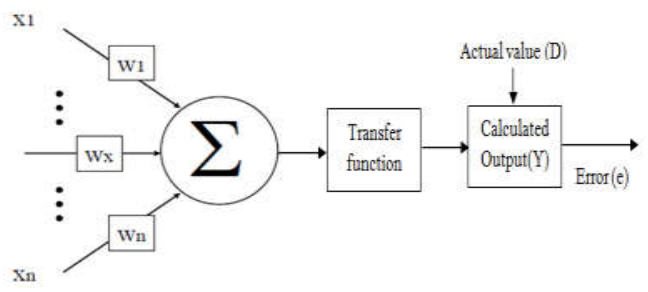

Fig. 4 Mcculloch Pitts Model of Artificial Neuron (Also Called Perceptron)

$\mathrm{X}_{1}, \mathrm{X}_{2}$ and $\mathrm{X}_{3}=$ Inputs, $\mathrm{W}_{1}, \mathrm{~W}_{2}$ and $\mathrm{W}_{3}=$ Synaptic weights, $\mathrm{T}$ $=$ Threshold

Transfer function: Examples are Sigmoid, Hyperbolic tangent etc.

$$
\sum=\text { summing junction }
$$

\section{Information Processing}

Weighted $\operatorname{sum}(\mathrm{V})=\mathrm{W}_{1} \cdot \mathrm{X}_{1}+\mathrm{W}_{2} \cdot \mathrm{X}_{2}+\mathrm{W}_{3} \cdot \mathrm{X}_{3}-\mathrm{T}$, for $\mathrm{i}=1,3, \mathrm{j}$ $=1,3$

Now the neuron fires only when $\mathrm{V} \geq 0$ and gives the output, generally using Sigmoid function (shown below); otherwise the output $=0.0$

$$
\text { Output }(\mathrm{Y})=\frac{1}{1+e^{-V}}
$$

\section{Back Propagation Neural Network (BPNN) Architecture}

This type of network shown in Fig.5 is sometimes called multilayer perception (MLP) because of its similarity to perception networks with more than one layer.

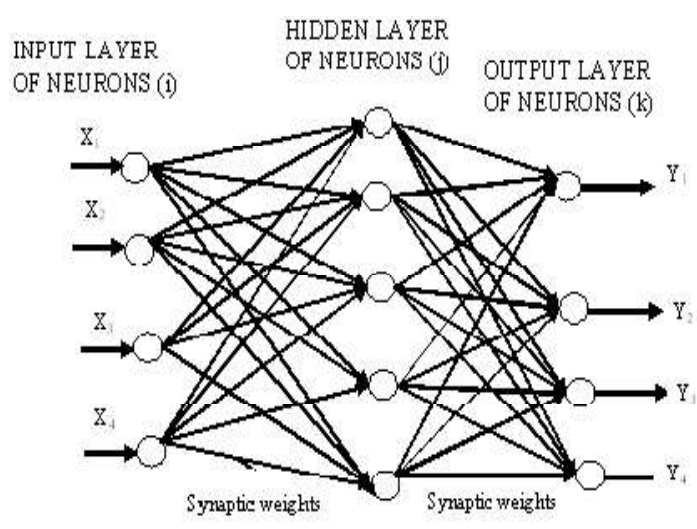

Fig 5. BPNN Architecture

The network consists of a number of layers called the input, hidden and output layers. The hidden and output layers contain a number of neurons or processing elements which are connected by links or connections to show the flow direction of signals and also to represent weight or strength of their respective connections. In an MLP of the back propagation type, the connections are first initialized by a set of uniformly distributed random numbers between 0 and 1.The calculations are made in feed forward manner until back propagation of errors is done. Following the processing in a single neuron (Fig. 4), outputs from the neurons of a certain layer (eq. 1) are given as inputs to the neurons of the next layer. Finally the output layer gives the calculated output $\left(\mathrm{Y}_{\mathrm{K}}\right)$ from the BPNN 


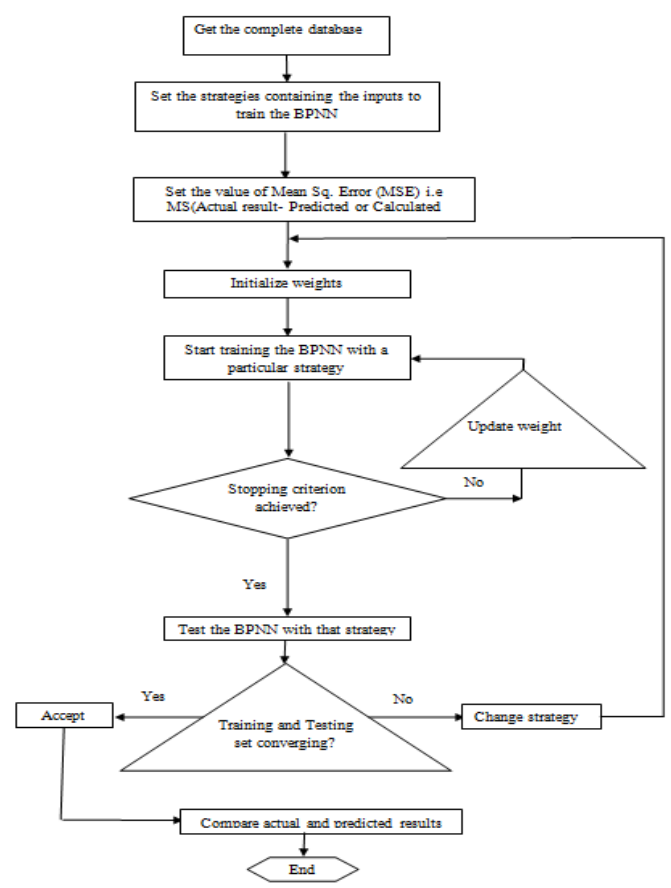

Fig.6 Flow chart of BPNN

and the back propagation begins on the basis of prediction error $\left(\mathrm{e}_{\mathrm{K}}\right)$. The flow chart shown in Fig. 3 summarizes the operation of BPNN:

The errors are:

$$
\text { RMS training error }=\sqrt{\frac{1}{2(N T R)} \sum_{n=1}^{N T R} \sum_{j \in C}\left[d_{K}^{T R}(n)-Y_{K}^{T R}(n)\right]^{2}}
$$

RMS testing error $=\sqrt{\frac{1}{2(N T S)} \sum_{n=1}^{N T S} \sum_{j \in C}\left[d_{K}^{T S}(n)-Y_{K}^{T S}(n)\right]^{2}}$

$\mathrm{TR}=$ training set, $\mathrm{TS}=$ testing set, $\mathrm{NTR}=$ no. of training set, NTS $=$ no. of testing set,

$\mathrm{C}=$ no. of output nodes.

The iterations may be stopped for any of the following reasons:

(a) Either after a certain number of iterations

(b) Or after a desired precision level is achieved

(c) Or the RMS Testing error begins to increase (called Over learning/Over training) shown next[5].

\section{Strategic Analysis}

The entire set of 63 data is divided into 42 nos. of training set and 21 nos. of testing set. The performance of the various input parameters for predicting the output $\left(\mathrm{NO}_{\mathrm{X}}\right.$ emission from the engine) are studied with the help of BPNN program. For this purpose, systemic analysis has been adopted by grouping the input parameters, which are being called as "strategies" listed in table 3 below.

Table 3 Strategies for analysing BPNN performance

\begin{tabular}{|c|c|c|c|}
\hline Strategy & Input parmeters & \begin{tabular}{|r|}
$\begin{array}{r}\text { Output } \\
\text { observed }\end{array}$ \\
\end{tabular} & Remark \\
\hline I & $\mathrm{CR}, \mathrm{IT}, \mathrm{W}_{\mathrm{OBS}}$ & \multirow{7}{*}{$\mathrm{NO}_{\mathrm{x}}$} & \multirow{7}{*}{$\begin{array}{c}\text { Basic strategy is } \\
\text { Strategy-I, which is } \\
\text { followed by gradual } \\
\text { addition and deletion } \\
\text { of other parameters } \\
\text { pbtained from sensors } \\
\text { signals. }\end{array}$} \\
\hline II & $\mathrm{CR}, \mathrm{IT}, \mathrm{W}_{\mathrm{OBS}}, \mathrm{PP}$ & & \\
\hline III & $\mathrm{CR}, \mathrm{IT}, \mathrm{W}_{\mathrm{OBS}}, \theta_{\text {peak }}$ & & \\
\hline IV & $\begin{array}{c}\mathrm{CR}, \mathrm{IT}, \mathrm{W}_{\mathrm{OBS}}, \\
\mathrm{PP}, \theta_{\text {peak }}\end{array}$ & & \\
\hline $\mathrm{V}$ & $\begin{array}{c}\text { CR, IT, } W_{\text {OBS }}, P P, \\
\theta_{\text {peak }}, \text { R.F.I } \\
\end{array}$ & & \\
\hline VI & $\begin{array}{l}\text { CR, IT, W } W_{\mathrm{OBS}}, \text { PP, } \\
\theta_{\text {peak }}, \text { Air pr., R.F.I }\end{array}$ & & \\
\hline VII & $\begin{array}{c}\mathrm{CR}, \mathrm{IT}, \mathrm{W}_{\mathrm{OBS}}, \mathrm{T}_{1}, \\
\mathrm{~T}_{2}, \mathrm{~T}_{5}, \mathrm{PP}, \theta_{\text {peak }}\end{array}$ & & \\
\hline
\end{tabular}

\section{Heuristic Optmization of BPNN and its parameters}

A. Firstly, the architecture of each strategy is optimized by changing the number of neurons in the hidden layer, keeping learning rate and momentum parameter[6,7] fixed respectively at 0.5 and 0.7 (the range being $0.1-20$ and $0.7-5$ for L.R and M.P respectively) to obtain a minimum mean squared error for the testing set of data or 25000 iterations, whichever occurs first

B. Secondly, the optimized architecture is further tested by varying the learning rate and momentum parameter to further minimise the error for the testing set The optimized results are obtained by iterating the training and testing set with the program using back propagation algorithm.

\section{The following inputs are fed to the program}

Learning Rate (LR), Momentum Parameter (MP), No. of layers (3), Architecture (input neurons, hidden neurons, output neurons), Iterations (25000), Display interval (5), and Desired mean squared error for testing data $\left(\mathrm{MSE}_{\mathrm{TS}}=0.001\right)$

\section{Result of analysis of $\mathrm{NO}_{\mathrm{x}}$}

Best results compiled for $\mathrm{NO}_{\mathrm{X}}$ emission are listed in Table 4. The learning curves and scatter diagrams of predicted and observed results for $\mathrm{NO}_{\mathrm{X}}$ emission are depicted from Fig. 7 and 8 .

Table 4 Best result for $\mathrm{NO}_{\mathbf{x}}$

\begin{tabular}{cccccccc}
\hline \multirow{2}{*}{ Strategy } & Architecture & L.R & M.P & \multicolumn{3}{c}{$\begin{array}{c}\text { Percent RMS } \\
\text { Error }\end{array}$} & Iteration \\
\cline { 5 - 6 } & & & & TRAIN & TEST & \\
VII & $8-10-1$ & 0.6 & 0.9 & 3.178 & 7.440 & 11375 \\
\hline
\end{tabular}

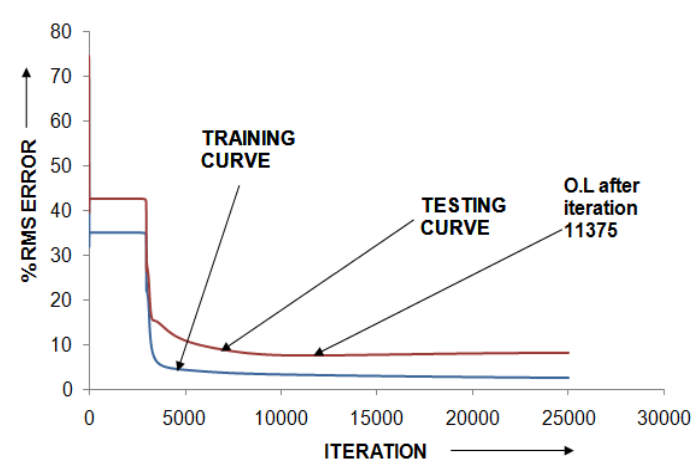

Fig.7 Learning curves for the heuristically best strategy VII of $\mathrm{NO}_{\mathrm{X}}$ 


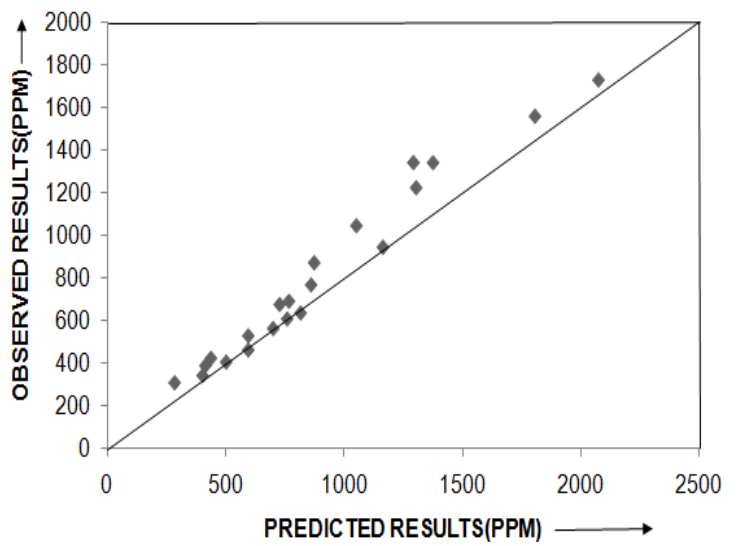

Fig.8 Observed V/S Predicted results for $\mathrm{NO}_{\mathrm{X}}$ at iteration 11375 for strategy VII

\section{Inference}

I. It has been tested that the three basic controllable parameters compression ratio, observed load and injection timing as inputs give bad result. The minimum difference between observed and predicted results of training and testing set of data for 25000 iterations amounts to $217.115 \mathrm{ppm}$ and $242.4328 \mathrm{ppm}$ respectively

II. The minimum difference between observed and predicted results of training and testing set of data for 25000 iterations amounts to $186.142 \mathrm{ppm}$ and $255.083 \mathrm{ppm}$ for strategy III and $167.743 \mathrm{ppm}$ and 251.806ppm for strategy IV

III. The inclusion of cylinder air pressure and fuel rate does not lead to any satisfactory result with the minimum difference between observed and predicted results of training and testing set of data for 25000 iterations amounts to $168.534 \mathrm{ppm}$ and $251.988 \mathrm{ppm}$

IV. Strategy VII which include temperature of water inlet and outlet to and from the engine respectively and engine exhaust temperature in combination with sensor signals such as peak cylinder pressure and crank angle at peak pressure yields the best result as is evident from Table 4 . The minimum difference between observed and predicted results of training and testing set of data for 25000 iterations amounts to $169.943 \mathrm{ppm}$ and $208.088 \mathrm{ppm}$ respectively. Fig. 7 and 8 indicates the result

\section{CONCLUSION}

As evident from the above analysis, strategy VII gives the predicted value of emissions close to their observed values. Strategy IV comes closer to VII. The temperature of water inlet and outlet to and from the engine respectively and engine exhaust temperature plays the most important role in emission prediction. It has been observed that the peak cylinder pressure and crank angle at peak pressure $\left(\boldsymbol{\theta}_{\text {peak }}\right)$ is a vital ingredient in $\mathrm{NO}_{\mathrm{X}}$ prediction whereas the inclusion of indicted air pressure (Air pr.) and rate of fuel input into the cylinder (R.F.I) as inputs to the BPNN lead to poorer results in emission prediction.

\section{References}

1. Karakitsios,Papaloukas C, Pilidis G, Kessomenos P, Development of an ANN to estimate traffic emissions in Athens, Greece, Proceedings of the $10^{\text {th }}$ International Conference on Harmonisation within Atmospheric dispersion Modelling for Regulatory Purposes, 2005

2. Obodeh et.al, Evaluation of Artificial Neural Network performance in predicting diesel engine $\mathrm{NO}_{\mathrm{x}}$ emission, European Journal of Scientific research, Vol.33, P.No. 4, 2009

3. M.Ali Akcayol et.al, Artificial Neural Network based modelling of heated Catalytic Converter performance, Applied Thermal Engineering, Volume 25, Issues 14-15, October 2005, Pages 2341-2350

4. Shivakumar et.al, Performance and emission characteristics of a 4 stroke C.I engine operated on honge methyl ester using artificial neural network, ARPN Journal of Engineering and Applied Sciences, Vol.5, June 6, 2010

5. Simon Haykin, Neural Networks:A comprehensive foundation, (PHI pulications, 1998)

6. R.C Chakraborty,Fundamentals of neural network, (http://www.myreaders.info)

7. S.Rajasekharan et.al, Neural networks, fuzzy logic and genetic algorithm, (PHI publications, 2011)

\section{How to cite this article:}

Aunshuman Chatterjee and Ranjit Kumar Dutta (2017) ' Application of back propagation neural network in predicting nox emission from I. C. Engines', International Journal of Current Advanced Research, 06(05), pp. 3791-3795.

DOI: http://dx.doi.org/10.24327/ijcar.2017.3795.0369 